Çukurova Üniversitesi Mühendislik Fakültesi Dergisi, 36(2), ss. 457-472, Haziran 2021

Cukurova University Journal of the Faculty of Engineering, 36(2), pp. 457-472, June 2021

\title{
L ve T Tesisat Bağlantı Elemanlarında Nanoakışkan Kullanımında Akış Karakteristiklerinin Sayısal Olarak İncelenmesi
}

\author{
Nehir TOKGÖZ ${ }^{* 1}$, Mürüvvet AVCI ${ }^{1}$, Mehmet Tahir ERDINNÇ${ }^{2}$, Önder KAŞKA ${ }^{3}$ \\ ${ }^{\text {I} O s m a n i y e ~ K o r k u t ~ A t a ~ U ̈ n i v e r s i t e s i, ~ M u ̈ h e n d i s l i k ~ F a k u ̈ l t e s i, ~ E n e r j i ~ S i s t e m l e r i ~ M u ̈ h e n d i s l i g ̆ i ~ B o ̈ l u ̈ m u ̈,, ~}$ \\ Osmaniye \\ ${ }^{2}$ Tarsus Üniversitesi, Mühendislik Fakültesi, Makine Mühendisliği Bölümü, Tarsus \\ ${ }^{3}$ Osmaniye Korkut Ata Üniversitesi, Mühendislik Fakültesi, Makine Mühendisliği Bölümü̈, Osmaniye
}

Geliş tarihi: 15.04.2021 Kabul tarihi: 30.06 .2021

$\ddot{\mathbf{O} z}$

Yapılan bu çalışmada endüstriyel sistemlerde en çok kullanılan 2 farklı tesisat bağlantı parçasının (L, T) içerisinden nanoakışkan geçirilip, bu bağlantı parçalarının basınç düşüşleri ve basınç kayıp katsayıları sayısal olarak incelenmiştir. Nanoakışkan, temel akışkan su alınarak içerisine farklı konsantrasyonlarda alüminyum, bakır ve titanyum esaslı nanoparçacıkların eklenmesiyle elde edilmiştir. Artan konsantrasyonun basınç kaybı ve akış yapısı üzerinde etkisini incelemek için farklı konsantrasyonlarda farklı nanoakışkanlar incelenmiştir $\left(\left(\mathrm{A}_{2} \mathrm{O}_{3}, \% 0,3, \% 0.5\right.\right.$, $\% 1, \% 2, \% 3)$ ve $\mathrm{CuO}(\% 1, \% 2, \% 4)$. Nanoakışkanların termofiziksel özellikleri daha önce yapılmış olan çalışmalardan alınmıştır. Hesaplama sonuçları, literatürdeki sonuçlar ile doğrulanmıştır. Sayısal çözümlemelerde yaygın olarak tercih edilen standart k- $\varepsilon$ ve standart k- $\omega$ türbülans modeli olmak üzere 2 farklı model kullanılmıştır. Elde edilen hesaplar sonucunda incelenen her akışkanda, konsantrasyon arttıkça viskozitenin artışı ile yerel kayıpların da arttı̆̆ ortaya konulmuştur. En uygun modelin her iki bağlantı parçası için de standart k- $\varepsilon$ olduğu belirlenmiştir.

Anahtar kelimeler: Bağlantı elamanı, Nanoakışkan, Yerel kayıp

\section{Numerical Investigation of Flow Characteristics of Nanofluid Usage in $L$ and $T$ Fittings}

\begin{abstract}
In this study, for two different most commonly used fittings $(\mathrm{L}, \mathrm{T})$ in industrial systems, effect of the nanofluid usage on the pressure drop and pressure loss coefficient were numerically analysed. Taking the water as base fluid, the nanofluid is obtained by adding different concentrations of aluminium, copper and titanium-based nanoparticles. In order to examine the effect of the concentration on pressure loss and flow structure, different nanofluids which are at different concentrations were studied $\left(\left(\mathrm{A}_{2} \mathrm{O}_{3}, 0.3 \%, 0.5 \%, 1 \%, 2 \%, 3 \%\right)\right.$ and $\mathrm{CuO}(1 \%$, $2 \%, 4 \%)$. The thermophysical properties of nanofluids were taken from previous studies. The results have been verified with the results to be given in the literature. Two different turbulent models were used for numerical analysis, the standard k- $\varepsilon$ and the standard $k-\omega$ turbulence model, which are widely preferred. The result of the computations for each nanofluid showed that as the concentration increases, the local losses increase with the increase of viscosity. It has been determined that the most suitable model is the standard k- $\varepsilon$ for both fittings.
\end{abstract}

Keywords: Fittings, Nanofluid, Local loss

"Sorumlu yazar (Corresponding author): Nehir TOKGÖZ, nehirtokgoz@osmaniye.edu.tr 


\section{GíRiș}

Günümüzde endüstrinin her alanında 1sı transferine yönelik yapılan araştırmaların temel amacı; enerjinin etkin ve verimli şekilde kullanılmasına yöneliktir. Enerji tüketen cihazların verimliliğini artırarak, mevcut enerjinin en iyi şekilde kullanılması araştırmacıların birinci hedefi haline gelmiştir. $\mathrm{Bu}$ kapsamda yapılan çalışmalar neticesinde 1sıyı transfer etmek için tasarlanan isı değiştiricilerinin verimlilik açısından daha etkili, maliyet açısından daha uygun olması amaçlanmıştır. Enerjiyi etkin şekilde kullanıp 1s1 transferini artırmaya yönelik çalışmalar aktif, pasif ve karma yöntemler olarak bilinmektedir. Pasif yöntemler, genişletilmiş yüzeyler, kanatçıklar gibi dış güç kullanılmasını gerektirmeyen yöntemlerken, aktif yöntemler de bir diş güç kaynağına ihtiyaç duyulur. Karma yöntemlerde ise aktif ve pasif yöntemlerden ikisi ya da daha fazlası birlikte kullanılır [1]. Isı transfer etkinliğini arttırmak için, iş yapan akışkanın (temel akışkan) içerisine mikro veya nano boyuttaki katı parçacıklar eklenerek yeni akışkan elde edilmesi günümüzde çok tercih edilen pasif yöntemlerden biridir. Burada amaç 1s1 transferini artırmaya yönelik olsa da özellikle boru sistemlerindeki akışkanlarda çökelme, tortulaşma gibi birçok dezavantajı da beraberinde getirmiştir. $\mathrm{Bu}$ gibi durumlar da, performansı düşürüp ısı değiştiricilerinin boyutunu ve maliyetini arttırmıştır [2].

Malzeme bilimi ve endüstrinin gelişmesiyle su, etilen, motor yağı gibi yaygın olarak kullanılan temel akışkanların içerisine ilave edilen partiküller mikro boyuttayken $(1 \mu \mathrm{m}=10-6 \mathrm{~m})$ yerini nano boyutlara (1 $\mathrm{nm}=10-9 \mathrm{~m})$ bırakmıştır. Temel akışkan içerisine; boyutu 100 nm'den daha düşük, 1sıl iletkenliği yüksek metalik ve metalik olmayan parçacıklar ilave edilerek nanoakışkan adı verilen yeni akışkanlar elde edilmiştir. Nanoakışkan kavramı ilk kez Choi ve arkadaşları tarafından ortaya konulmuştur. Nanoakışkanların tercih edilme nedenlerinin başında 1sı iletim katsayılarını geleneksel akışkanlara göre çok yüksek olması ve basınç düşümünü çok fazla arttırmamalarıdır. Böylece yüksek 1sı transfer performansı ile daha küçük boyutlarda 1sı değiştiricisi yapma imkanı sunmaktadır [3]. Nano parçacıkların aynı hacimsel konsantrasyonda mikro parçacıklara kıyasla daha fazla yüzey alanına sahiptir. Mikro boyuttaki partiküllerle hazırlanan süspansiyonların kanallarda tıkanmalara sebep olurken [4] nanoparçacıkların boru içerisinde çökelme ve tortulaşma meydan getirmediği ve akış boyunca kanalı aşındırmadığı görülmüştür. Ayrıca nanoakışkan kullanımı mikro kanal yüzey ile akışkan arasındaki sıcaklık farkını azaltıp, ısıl direncin azalmasına yol açmıştır. Bütün bunların sonucunda araştırmacılar nano boyutlu katı parçacıkların kullanılmasıyla ısı transferinin büyük ölçüde iyileştirilebileceğini görmüşlerdir. $\mathrm{Bu}$ olumlu sonuçlar neticesinde de güneş kolektörleri, 1sı boruları, nükleer reaktörler, elektronik soğutma sistemleri, otomobil radyatörleri vb. uygulamalar için muhtemel çalışma sıvıları olarak kabul edilebileceği düşünülmüştür [5-7]. Son y1llarda yapılan teorik ve deneysel çalışmalar nanoakışkanlardaki nanoparçacıkların boyut, konsantrasyon, yoğunluk, viskozite, 1sıl iletkenlik gibi özelliklerinin 1S1 transferi üzerine etkilerini incelemeye yöneliktir. Ahmed ve arkadaşları 1sitılan oluklu kanal üzerinden bakır-su nanoakışkanının 1s1 transferi ve basınç düşüşü sayısal olarak incelemişlerdir. Elde ettikleri sonuçlara göre 1sı transferinin, Reynolds sayısı ve nano parçacık hacim fonksiyonu arttıkça arttığ1 ancak basınç düşüşünde de hafif bir artış olduğunu görmüşlerdir [8]. Sasmito ve arkadaşları, yaptıkları çalışma da helezon şeklinde sarılmış kare kesitli bir tüpün içerisinden nanoakışkan geçirerek 1s1 transferini arttırmayı amaçlamışlardır. Nanoparçacık olarak $\mathrm{Al}_{2} \mathrm{O}_{3}$ ve $\mathrm{CuO}$ kullandıkları çalışmalarının sonuçlarını düz tüp akış davranışlarıyla karşılaştırmışlardır. Elde ettikleri sonuçlara göre \%1'e kadar olan nano parçacık ilavesinin 1s1 transfer performansını önemli ölçüde artırdığını daha fazlasının ise 1Sı transfer performansını bozma eğiliminde olduğunu iddia etmişlerdir [9]. Nanoakışkanların 1sı transferini arttırıp geliştirdiğini Brownian hareketi ve termofiziksel özelliklere değinerek açıklayan Godson ve arkadaşları, mühendislerin son derece kompakt ve etkili 1s1 transfer ekipmanları geliştirmeleri için bir firsat sunabileceğini vurgulamışlardır. Nanoakışkanların 1sı transfer katsayısının, temel bazlı akışkanın 1sı transfer katsayısından çok daha yüksek olduğunu ve çok az basınç düşüşüne sebep olduğunu görmüşlerdir. 
Taşınım 1sı transferinin, parçacık konsantrasyonu ve Reynolds sayısı ile arttığını ifade etmişlerdir [10]. Mikro veya makro boyuttaki 1sı değiştiriciler üzerine çalışmalar yapan Manay vd. mikro kanallı yüzeylerde daha çok 1sı transferi yapılabildiğini savunmuşlardır. Fakat partiküllerin varlığının kanallar içerisinde basınç düşümüne neden olabileceğini söylemişlerdir [11]. Helisel kıvrımlı bir boruda farklı konsantrasyonlarda $\mathrm{CuO}$ nanoakışkanının 1Sı transfer katsayısı ve basınç düşüşünü değerlendiren Hashemi ve arkadaşları., elde ettikleri sonuçlara göre; düz boru yerine kıvrımlı boru kullanmanın ısı transferini arttırdığı, 1S1 transfer katsayısı ve basınç düşüşünün baz sıvıs1 yerine nanoakışkan kullanılarak arttığını savunmuşlardır [12]. Ahmed ve arkadaşları, iki boyutlu dalgalı bir kanaldaki laminar akışta bakırsu nanoakışkanının 1sı transferini sayısal olarak incelemişlerdir. Dalgalı kanalın genliği arttıkça sürtünme katsayısının ve Nusselt sayısının da arttığını görmüşlerdir. Buna ek olarak, 1s1 transferindeki artışın ağırlıklı olarak dalga boyundan ziyade nano partikül hacim konsantrasyonuna, dalgalı duvarın genliğine ve Reynolds sayısına bağlı olduğunu bulmuşlardır [13]. Oluklu plakalardan oluşan bir 1s1 değiştiricisinde su- $\mathrm{Al}_{2} \mathrm{O}_{3}$ nanoakışkanı geçirilmesi durumunda 1s1 transfer katsayısını ve basınç düşüşünü inceleyen Kabeel vd. elde ettikleri sonuçları teorik bir modelle karşılaştırıp doğrulamışlardır. Konsantrasyonunun arttırılmasıyla hem 1s1 transfer katsayısında hem de aktarılan güçte belirgin bir artış gözlemişlerdir. Ayrıca basınç düşüşüne bağlı olarak gerekli pompalama gücünün ise konsantrasyon ve Reynolds sayının artmasıyla arttığ 1 sonucuna ulaşmışlardır [14]. Chavda ve arkadaşları, farklı tip bağlantı parçalarındaki yerel kayıp katsayısını ve sürtünme faktörünü incelemek için suya farklı konsantrasyonlarda $\mathrm{Al}_{2} \mathrm{O}_{3}$ ekleyerek deneysel bir çalışma gerçekleştirmişlerdir. Bağlantı parçalarında nanoakışkan kullanılması durumunda ulaştıkları sonuçları su ile kıyaslamışlardır. Araştırmacılar yaptıkları deneysel verilerden elde ettikleri bulgulara göre; suya kiyasla $\mathrm{Al}_{2} \mathrm{O}_{3}{ }^{\prime}$ in hacim konsantrasyonu arttıkça farklı bağlantı parçalarının sürtünme faktörü ve yerel kayıp katsayısının arttığını savunmuşlardır [15]. Barik ve arkadaşları, $90^{\circ}$ dirsek bağlantı parçasından $\mathrm{Al}_{2} \mathrm{O}_{3}, \mathrm{Ti}_{2} \mathrm{O}$ ve $\mathrm{CuO}$ nanoakışkanlarını geçirip sonlu hacimler yöntemi kullanarak 1sı transferinin değişimini incelemişlerdir. Sayısal çalışmalar sonucunda nanoakışkanların hacim konsantrasyonlarının değişiminin 1S1 transferini önemli ölçüde arttığını görmüşlerdir ve 1sı transferindeki en fazla artışın $\mathrm{CuO}$ nanoakışkanında olduğunu görmüşlerdir [16]. Vasa ve arkadaşları, $180^{\circ}$ üçgen kesitli bir U bağlantı parçasında $\mathrm{Al}_{2} \mathrm{O}_{3}$ nanoakışkanın farklı konsantrasyonlarında 1s1 transfer karakteristiklerini sayısal olarak incelemişlerdir. Elde ettikleri sonuçlara göre Reynolds sayısının ve nanoakışkanın hacim konsatrasyonu arttıkça bağlantı parçasının 1sı transferinde de önemli bir artış olduğunu gözlemlemişlerdir [17].

Yapılan çalışmaların birçoğunun sonucunda nanoakışkanların 1sı transferini artırdı ̆̆ vurgulansa da yapılan deneylerle birlikte incelenen sonuçlar her zaman bunu doğrulamamaktadır. Mohamad yaptığı çalışmasında temel akışkana nanoparçacıkların eklenmesiyle etkin viskozitenin artacağını bunun sonucunda da basınç düşüşünün olumsuz etkileneceğini ve bu parçacıkların yüzeye çarparak erozyonları artabileceğini belirtmiştir [18].

Sunulan bu çalışmada tesisatlarda en çok kullanılan $\mathrm{L}$ ve $\mathrm{T}$ bağlantı parçalarının içerisinden nanoakışkan geçirilmesiyle oluşan basınç farkı ve yerel kayıp katsayısı sayısal olarak hesaplanmış, basınç ve hız dağılımları görselleştirilmiştir. Tesisat projeleri düşünüldüğünde; sistemin doğru ve ekonomik açıdan uygun tasarlanabilmesi için bu sistemlerdeki yerel kayıplar ve sürtünme kayıpları doğrudan pompa gücüne etki edeceğinden oldukça önemlidir. Daha önce yapılan çalışmalar incelendiğinde 1s1 transferinin nanoakışkanların hacim konsantrasyonları ile arttığı fakat sürtünme kayıplarını da beraberinde getirdiği göz önünde bulundurularak, tesisat bağlantı malzemelerini içinden farklı hacim konsantrasyonlarında alüminyum, titanyum ve bakır esaslı nano parçacıklar ilavesiyle elde edilen nanoakışkanlar geçirilmiştir. Elde edilen basınç düşüşleri suyla kıyaslanıp bağıl yerel kayıp katsayıları sayısal çalışma sonucunda elde edilmiştir. $\mathrm{Al}_{2} \mathrm{O}_{3}$ için beş, $\mathrm{CuO}$ için üç, $\mathrm{Ti}_{2} \mathrm{O}$ için ise dört farklı hacim konsantrasyonu seçilmiştir. Seçilen nanoakışkanların termofiziksel özellikleri 
L ve T Tesisat Bağlantı Elemanlarında Nanoakışkan Kullanımında Akış Karakteristiklerinin Sayısal Olarak Incelenmesi

literatürdeki çalışmalardan alınmıştır. Yapılan çalışma akışkan olarak su seçilip literatürde yaygın olarak kullanılan sonuçlarla [19] mukayese edilmiştir.

\section{MATERYAL VE YÖNTEM}

\subsection{Modelin Tanımlanması}

İncelenen bağlantı malzemeleri ANSYS- Fluent paket programında üç boyutlu modellenerek çözülmüştür. L ve T bağlantı parçası olmak üzere 2 farklı bağlantı parçası incelenmiştir. Modellenen parçaların boyutları giriş çapı, d ile boyutsuzlaştırılarak aşağıdaki çizelgede verilmiştir. Akışın tam gelişmiş olması için hidrodinamik giriş uzunlukları, $\quad \mathrm{L}_{\mathrm{h}}=10 \mathrm{~d}$ olarak alınmıştır. $\mathrm{Bu}$ çalışmada, Reynolds sayısı 5000 olarak belirlenmiştir. Reynolds sayısı Eşitlik 1'de gösterildiği şekilde tanımlanmıştır;

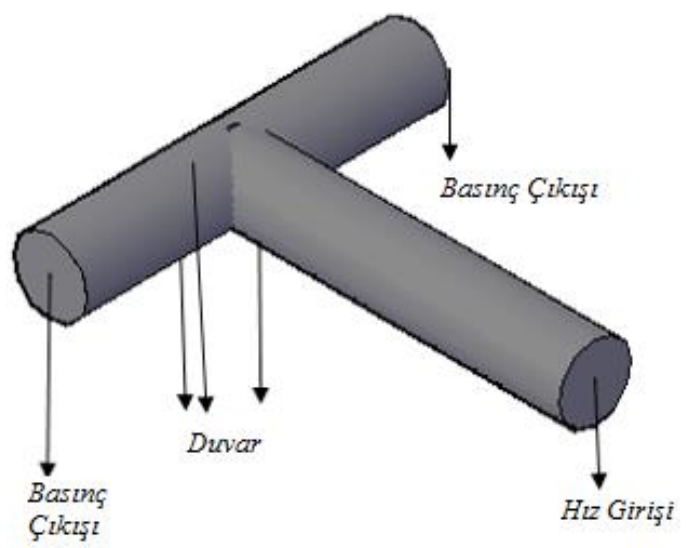

T bağlantı parçasının modeli ve sınır şartları
Reynolds $=\frac{\rho V d}{\mu}$

Burada $\rho, \mathrm{V}$, d ve $\mu$ sırasıyla akışkanın yoğunluğu $\left(\mathrm{kg} / \mathrm{m}^{3}\right)$, ortalama akış hızı $(\mathrm{m} / \mathrm{s})$, çap $(\mathrm{m})$ ve $\mu$ dinamik viskozitedir $\left(\mathrm{kg} / \mathrm{m}^{*} \mathrm{~s}\right)$. Kullanılan bağlantı malzemelerinin 3 boyutlu şematik gösterimi ve uygulanan sınır şartları aşağıdaki Şekil 1'de boyutları ise Çizelge 1'de özetlenmiştir.

Çizelge 1. Kullanılan bağlantı parçalarının boyutları

\begin{tabular}{|c|c|c|c|c|}
\hline \multirow[t]{2}{*}{ Parça } & \multirow{2}{*}{$\begin{array}{c}\text { Giriş } \\
\text { çapı } \\
\text { (m) }\end{array}$} & \multirow{2}{*}{$\begin{array}{c}\text { Çıkış } \\
\text { çapı } \\
(\mathbf{m})\end{array}$} & \multicolumn{2}{|c|}{$\begin{array}{c}\text { Uzunluğu } \\
(\mathbf{m})\end{array}$} \\
\hline & & & $\mathbf{x}$ & $\mathbf{x}$ \\
\hline $\mathrm{L}$ & $\mathrm{d}$ & $\mathrm{d}$ & $25 d$ & $25 d$ \\
\hline $\mathrm{T}$ & $\mathrm{d}$ & $\mathrm{d}$ & $25 d$ & $25 d$ \\
\hline
\end{tabular}

Sekil 1. Bağlantı malzemelerinin 3 boyutlu şematik gösterimi ve uygulanan sınır şartları

\subsection{Modellerin Sınır Sartları}

Tüm bağlantı parçalarında akışkanın girişi için üniform hız sınır şartı, çıkışı için ise basınç çıkışı sınır şartı ile tanımlanmıştır. Akışın hidrodinamik olarak gelişmesini sağlamak ve çıkış etkilerini azaltmak için giriş bölgesi uzunluğu $\left(\mathrm{L}_{\mathrm{g}}\right)$ ve çıkış bölgesi uzunluğu $\left(\mathrm{L}_{\mathrm{c}}\right)$ inceleme bölgesinde $10 \mathrm{~d}$ uzakta alınmıştır. Bağlantı parçalarının girişlerine 'hız giriși', çıkıșlarına 'basınç çıkıșı' ve boru cidarlarına 'duvar' sınır şartları tanımlanmıştır.

\subsection{Sayısal Metot ve Denge Denklemleri}

Üç boyutlu Reynolds Ortalamalı Navier-Stokes (RANS) denklemleri ayrık kapalı çözücü kullanılarak (segregated implicit solver) çözümlenmiştir. Denklem çözümlerinden basınç için Standart, momentum ve enerji denklemleri için ikinci derece upwind ayrıklaştırma algoritmaları kullanılmıştır. Yakınsama kriteri tüm denklemler için $10^{-6}$ olarak belirlenmiştir. 
Süreklilik denklemi (Eşitlik 2):

$\frac{\partial u}{\partial x}+\frac{\partial v}{\partial y}+\frac{\partial w}{\partial z}=0$

Momentum denklemi (Eşitlik 3):

$\frac{\partial\left(\rho u_{i} u_{j}\right)}{\partial x_{j}}=-\frac{\partial p}{\partial x_{i}}+\frac{\partial}{\partial x_{j}}\left[\mu\left(\frac{\partial u_{i}}{\partial x_{j}}+\frac{\partial u_{j}}{\partial x_{i}}\right)-\rho \overline{u_{i}^{\prime} u_{j}^{\prime}}\right]$

\subsubsection{Türbülans Modelleri}

Özellikle endüstriyel uygulamalarda seçilen türbülans modelli çok önemlidir. Türbülanslı akışların hız alanları çalkantılarla belirlenir. Kütle, momentum, enerji gibi büyüklükler akışta dönen bu girdaplar sayesinde taşınırlar. Mühendislik hesaplamalarında bu çalkantıların hesaplanması çok önemli olmasına rağmen doğrudan analiz etmek oldukça zordur. Türbülans modelinin seçiminde akışın fiziği, seçilen modelin sınırları ve daha önce yapılan çalışmaların sonuçları önem teşkil etmektedir. Bu çalışmada modeller arasındaki farklıkları ortaya koyabilmek için k- $\varepsilon$ ve $\mathrm{k}-\omega$ türbülans modelleri kullanılmıştır. Standart k$\varepsilon$ türbülans modeli iki denklemli türbülans modelleri arasında ekonomikliği ve pek çok akış probleminde kabul edilebilir doğrulukta sonuç vermesi açısından yaygın olarak kullanılan yarı ampirik bir modeldir. Dirseklerde, bükümlü borularda hem tek fazlı hem de iki fazlı akışlarda yüksek doğrulukta sonuçlar vermektedir [20-22]. $\mathrm{Bu}$ modelde türbülans kinetik enerji, $\mathrm{k}$ ve türbülans dağılım hızı, $\varepsilon$ aşağıda verilen denklemlerle çözülür (Eşitlik 4-5).

$$
\begin{aligned}
& \frac{\partial\left(u_{j} k\right)}{\partial t}=\mu_{t} \frac{\partial u_{i}}{\partial x_{j}}\left(\frac{\partial u_{i}}{\partial x_{j}}+\frac{\partial u_{j}}{\partial x_{i}}\right)+ \\
& \frac{\partial}{\partial x_{j}}\left(\frac{\mu_{t}}{\sigma_{k}} \frac{\partial_{k}}{\partial x_{j}}\right)-\rho \epsilon \\
& \frac{\partial\left(u_{j} \epsilon\right)}{\partial t}=C_{\epsilon 1} \frac{\epsilon}{k} \mu_{t} \frac{\partial u_{i}}{\partial x_{j}}\left(\frac{\partial u_{i}}{\partial x_{j}}+\frac{\partial u_{j}}{\partial x_{i}}\right)+ \\
& \frac{\partial}{\partial x_{j}}\left(\frac{\mu_{t}}{\sigma_{k}} \frac{\partial_{\epsilon}}{\partial x_{j}}\right)-\rho C_{\epsilon 2} \frac{\epsilon^{2}}{k}
\end{aligned}
$$

Burada $k, \varepsilon, \sigma_{k}$ sirasıyla; türbülans kinetik enerjisi, enerjinin yayılımı ve türbülanslı Prandtl sayısıdır. Türbülans Eddy viskozitesi ise (Eşitlik 6):

$$
\mu_{t}=C_{\mu} \frac{k^{2}}{\varepsilon}
$$

Burada $\mathrm{C}_{\mu}, \mathrm{C}_{\varepsilon 1}, \mathrm{C}_{\varepsilon 2}$ model katsayılarıdır ve şu şekilde ifade edilir (Eşitlik 7-8):

$$
C_{\mu}=\left(\frac{u_{*}^{2}}{k}\right)^{2}
$$

$$
C_{\varepsilon 1}=C_{\varepsilon 2}-\frac{\kappa}{\sqrt{ } C_{\mu} \sigma_{\varepsilon}}
$$

$\mathrm{u}_{*}$ : Sürtünme hızı, Çözümlemede kullanılan model sabitleri ise:

$\mathrm{C}_{\epsilon 1}=1,44, C_{\epsilon 2}=1,92, C_{\mu}=0,09, \sigma_{k}=1.0, \sigma_{\epsilon}=1,3$

Endüstriyel uygulamalarda sıklıkla kullanılan bir diğer türbülans modeli de $\mathrm{k}-\varepsilon$ türbülans modeline benzeyen standart k- $\omega$ türbülans modelidir. Sınır tabaka akışlarında, serbest kayma tabakalı akışlarda ve düşük Reynolds sayılı akışlarda k- $\varepsilon$ türbülans modellerine göre daha üstündür. Ters basınç gradyanı altındaki ve büyük akış ayrılmalarının olduğu sınır tabaka akışlarında (diş akış aerodinamik ve turbomakine uygulamalarında) kullanılmaktadır. Yine benzer şekilde k türbülans kinetik enerjisi, $\omega$ ise enerjinin yayılımının aşağıdaki şekilde yazılabilir [23].

$$
\begin{aligned}
& \frac{\partial k}{\partial t}+u_{j} \frac{\partial k}{\partial x_{j}}=\tau_{i j} \frac{\partial u_{i}}{\partial x_{j}}-\beta^{*} k \omega \frac{\partial}{\partial x_{j}} \\
& {\left[\left(v+\sigma^{*} v_{T}\right) \frac{\partial k}{\partial x_{j}}\right]} \\
& \frac{\partial \omega}{\partial t}+u_{j} \frac{\partial \omega}{\partial x_{j}}=\alpha \frac{\omega}{k} \tau_{i j} \frac{\partial u_{i}}{\partial x_{j}}-\beta \omega^{2}+ \\
& \frac{\partial}{\partial x_{j}}\left[\left(v+\sigma v_{T}\right) \frac{\partial \omega}{\partial x_{j}}\right]
\end{aligned}
$$


L ve T Tesisat Bağlantı Elemanlarında Nanoakışkan Kullanımında Akış Karakteristiklerinin Sayısal Olarak Incelenmesi

Burada kinematik Eddy viskozitesi şu şekilde ifade edilir:

$v_{T}=\frac{k}{\omega}$

$\alpha, \beta, \beta^{*}, \sigma$ ve $\sigma^{*}$ model katsayılarıdır ve sirayla $5 / 9$, $3 / 40,9 / 100,1 / 2$ ve $1 / 2$ değerlerine eşittir.

\subsection{Yerel Kayıplar ve Kayıp Katsayısı}

Akış problemlerinde göz önünde bulundurulması gereken en önemli etken, borudaki akışın rejimi, borunun fiziksel boyutları, boru malzemesi, akışkanın yön değiştirmesini sağlayan veya boruları birleştirmek için kullanılan bağlantı malzemelerinde meydana gelen enerji kayıplarıdır. Akışkanı bir yerden başka bir yere taşımak için kullanılan pompalar oluşan bu enerji kayıplarını karşılayacak şekilde seçilirler. Bu sebeple meydana gelen kayıplar ne kadar küçük olursa seçilen pompa da o kadar küçük boyutlarda olacak böylece enerji tasarrufu sağlanmış olacaktır. Bir boru akışında sürtünmeden kaynaklanan kayıplar sürekli yük kayıpları diye adlandırılırken bağlantı malzemelerinin neden olduğu kayıplar yerel kayıplar olarak adlandırılmaktadır. Bu bağlantı elemanlarına örnek olarak; sürekli daralıp, genişleyen borularda geçişi kolaylaştıran difüzörler, giriş ve çıkış çaplarındaki ani genişleme ve ani daralmalar, T geçişi, akışı kontrol edip yönlendiren vanalar sayılabilir. Bu bağlantı elemanlarında yerel yük kayıpları (m) aşağıda verilen ifade ile hesaplanabilir;

$H_{k}=\frac{\Delta P}{\rho g}=K_{k} \frac{V^{2}}{2 g}$
$H_{k}$ : yerel yük kaybı(m), $\Delta P$ : iki nokta arasındaki basınç farkı $(\mathrm{Pa}), \rho$ : suyun yoğunluğu $\left(\mathrm{kg} / \mathrm{m}^{3}\right)$, $g$ : yerçekimi ivmesi $\left(9,81 \mathrm{~m} / \mathrm{s}^{2}\right), K_{k}$ : yerel kayıp katsayısı, $V$ : ortalama akış hızıdır $(\mathrm{m} / \mathrm{s})$

\subsection{Pompa Gücü}

Pompalar dışarıdan aldıkları enerjiyi akış enerjisine dönüştürüp, akışkanı bulunduğu noktadan istenilen noktaya taşır, boru içinden geçen akışkanı basınçlandırarak yukarıda bahsedilen kayıpları karşılayan enerjiyi sağlarlar. Bir pompanın gücü, aşağıdaki eşitlikten hesaplanabilir.

$$
W=\dot{w} \cdot \Delta P
$$

Burada $\mathrm{W}, \dot{W}, \Delta \mathrm{P}$ sırasıyla; akışkana aktarılan faydalı güç (Watt), hesaplanan hacimsel debi $\left(\mathrm{m}^{3} / \mathrm{s}\right)$ ve pompa giriş ve çıkışı arasında ölçülen basınç farkıdır.

\subsection{Nanoakışkanların Termofiziksel Özellikleri}

Temel akışkan su alınarak içerisine farklı konsantrasyonlarda $\mathrm{Al}_{2} \mathrm{O}_{3}$ ve $\mathrm{CuO}$ esaslı nano parçacık ilave edilerek homojen nanoakışkanlar elde edildiği kabul edilmiştir. Beş farklı konsantrasyonda $\mathrm{Al}_{2} \mathrm{O}_{3}(\% 00,3, \% 0,5, \% 1, \% 2$, $\% 3)$, üç farklı konsantrasyonda $\mathrm{CuO}(\% 1, \% 2, \% 4)$ ve $\mathrm{Ti}_{2} \mathrm{O}(\% 0,05, \% 0,1, \% 0,3, \% 0,5)$ kullanılmıştır. Her bir konsantrasyon için ayrı ayrı hesaplama yapılmıştır. Kullanılan nanoakışkanların termofiziksel özellikleri daha önce literatürde yapılan deneysel çalışmalardan alınarak aşağıdaki Çizelge 2-4'de özetlenmiştir.

Çizelge 2. $20^{\circ} \mathrm{C}$ 'de alüminyum oksidin, $\mathrm{Al}_{2} \mathrm{O}_{3}$ fiziksel özellikleri [24]

\begin{tabular}{|l|c|c|c|c|}
\hline \multirow{2}{*}{ Akışkanlar } & \multicolumn{4}{|c|}{ Fiziksel özelikler } \\
\cline { 2 - 5 } & $\begin{array}{c}\text { Yoğunluk, } \\
\boldsymbol{\rho}\left(\mathbf{k g} / \mathbf{m}^{3}\right)\end{array}$ & $\begin{array}{c}\text { Özgül ISı, } \\
\boldsymbol{C}_{\boldsymbol{p}} \text { (j/kg K) }\end{array}$ & $\begin{array}{c}\text { Dinamik viskozite, } \boldsymbol{\mu} \\
(\mathbf{k g} / \mathbf{m s})\end{array}$ & $\begin{array}{c}\text { Isı iletim katsayıSı, } \\
\boldsymbol{K}(\mathbf{W} / \mathbf{m ~ K} \mathbf{)}\end{array}$ \\
\hline $\mathrm{Su}$ & 998,2 & 4182,0 & 0,001003 & 0,6 \\
\hline $\mathrm{Su}+\% 0,3 \mathrm{Al}_{2} \mathrm{O}_{3}$ & 1005,80 & 4145,20 & 0,0010862 & 0,608334 \\
\hline $\mathrm{Su}+\% 0,5 \mathrm{Al}_{2} \mathrm{O}_{3}$ & 1011,87 & 4110,86 & 0,00117021 & 0,619223 \\
\hline $\mathrm{Su}+\% 1,0 \mathrm{Al}_{2} \mathrm{O}_{3}$ & 1028,20 & 4036,67 & 0,00139827 & 0,644465 \\
\hline $\mathrm{Su}+\% 2,0 \mathrm{Al}_{2} \mathrm{O}_{3}$ & 1055,48 & 3925,80 & 0,0019319 & 0,685893 \\
\hline $\mathrm{Su}+\% 3,0 \mathrm{Al}_{2} \mathrm{O}_{3}$ & 1083,60 & 3810,77 & 0,0025689 & 0,728339 \\
\hline
\end{tabular}


Çizelge 3. $20^{\circ} \mathrm{C}$ 'de bakır oksidin, $\mathrm{CuO}$ fiziksel özellikleri [25]

\begin{tabular}{|c|c|c|c|c|}
\hline \multirow{2}{*}{ Akışkanlar } & \multicolumn{4}{|c|}{ Fiziksel özelikler } \\
\cline { 2 - 5 } & $\begin{array}{c}\text { Yoğunluk, } \\
\boldsymbol{P}\left(\mathbf{k g} / \mathbf{m}^{\mathbf{3}}\right)\end{array}$ & $\begin{array}{c}\text { Özgül ISı, } \\
\boldsymbol{C}_{\boldsymbol{p}}(\mathbf{j} / \mathbf{k g ~ K})\end{array}$ & $\begin{array}{c}\text { Dinamik viskozite, } \boldsymbol{\mu} \\
(\mathbf{k g} / \mathbf{m s})\end{array}$ & $\begin{array}{c}\text { Isı iletim katsayısı, } \\
\boldsymbol{k}(\mathbf{W} / \mathbf{m} \mathbf{K})\end{array}$ \\
\hline $\mathrm{Su}+\% 1 \mathrm{CuO}$ & 1051,418 & 4145,615 & 0,001387 & 0,645 \\
\hline $\mathrm{Su}+\% 2 \mathrm{CuO}$ & 1104,636 & 4109,150 & 0,001545 & 0,657 \\
\hline $\mathrm{Su}+\% 4 \mathrm{CuO}$ & 1211,072 & 4036,221 & 0,001762 & 0,694 \\
\hline
\end{tabular}

Çizelge 4. $20^{\circ} \mathrm{C}^{\prime}$ de titanyum oksidion, $\mathrm{Ti}_{2} \mathrm{O}$ fiziksel özellikleri [26]

\begin{tabular}{|c|c|c|c|c|}
\hline \multirow{2}{*}{ Akışkanlar } & \multicolumn{4}{|c|}{ Fiziksel özelikler } \\
\cline { 2 - 5 } & $\begin{array}{c}\text { Yoğunluk, } \\
\boldsymbol{\rho}\left(\mathbf{k g} / \mathbf{m}^{\mathbf{3}}\right)\end{array}$ & $\begin{array}{c}\text { Özgül ISı, } \\
\boldsymbol{C}_{\boldsymbol{p}}(\mathbf{j} / \mathbf{k g ~ K})\end{array}$ & $\begin{array}{c}\text { Dinamik viskozite, } \boldsymbol{\mu} \\
(\mathbf{k g} / \mathbf{m s})\end{array}$ & $\begin{array}{c}\text { Isı iletim katsayıSı, } \\
\boldsymbol{k}(\mathbf{W} / \mathbf{m} \mathbf{K})\end{array}$ \\
\hline $\mathrm{Su}+\% 0,05 \mathrm{Ti}_{2} \mathrm{O}$ & 1077,3 & 3858,3 & 0,000845 & 0,6569 \\
\hline $\mathrm{Su}+\% 0,1 \mathrm{Ti}_{2} \mathrm{O}$ & 1154,6 & 3573,7 & 0,000892 & 0,6953 \\
\hline $\mathrm{Su}+\% 0,3 \mathrm{Ti}_{2} \mathrm{O}$ & 1463,6 & 2736,8 & 0,001082 & 0,8656 \\
\hline $\mathrm{Su} \% 0,5 \mathrm{Ti}_{2} \mathrm{O}$ & 1771,9 & 2192,8 & 0,001271 & 1,068 \\
\hline
\end{tabular}

\section{BULGULAR VE TARTIŞMA}

$\mathrm{Bu}$ bölümde farklı hacim konsantrasyonlarında incelenen $\mathrm{Al}_{2} \mathrm{O}_{3}, \mathrm{CuO}$ ve $\mathrm{Ti}_{2} \mathrm{O}$ nanoakışkanların simülasyonlardan elde edilen sonuçlar açıklanmıştır. Sayısal sonuçlardan hesaplanan yerel kayıp katsayısı literatürde türbülanslı akış için kabul görmüş [19] yerel kayıp katsayıları ile kıyaslanmıştır.

Çözümlemeler sonucunda hangi türbülans modelinin referans alınan kaynağa en yakın sonuçlar verdiği tespit edilerek uygun modele karar verilmiştir. Aradaki farkın büyüklügünü ortaya koymak için kullanılan modellerin hepsi için sonuçlar ayrı ayrı çizelge ve grafikler halinde sunulmuştur. Kullanılan her nanoakışkan için elde edilen sonuçlar ayrı başlıklar halinde devam eden bölümlerde verilmiştir.

\subsection{Sonuçların Doğrulanması}

Literatürde yaygın olarak kullanılan Çengel ve arkadaşları [19] tarafından belirlenen kayıp katsayıları, $\mathrm{K}_{\mathrm{k}}$ ile iki farklı türbülans modeli kullanılarak yapılan sayısal çalışmadan hesaplanan değerler Çizelge 5' de mukayese edilmiştir. Sunulan bu çalışmada $\mathrm{K}_{\mathrm{k}}$ hesaplanırken nanoakışkanlarda da suyun yoğunluğu referans yoğunluk olarak kullanılmıştır. Elde edilen sonuçlara göre k- $\mathrm{\varepsilon}$ türbülans modeli ile elde edilen sonuçlar en yakın fark \%0,8 ile T bağlantı parçasında, en büyük fark \%5,5 ile L bağlantı parçasında hesaplanmıştır. Genel olarak bakıldığında sayısal ve deneysel sonuçlar arasındaki farklılı bu modelde $\% 0,4-\% 3,7$ arasındadır. k- $\omega$ türbülans modeli ile elde edilen sonuçlarda ise en yakın fark $\% 8$ ile $\mathrm{T}$ bağlantı parçasında, bağlantı parçasında hesaplanmıştır. Bütün bağlantı parçalarının kayıp katsayıları literatürdeki yerel kayıp katsayısı [19] ile mukayese edildiğinde, k- $\omega$ Standart modelinin kullanılması durumunda yerel kayıp katsayısı değerlerinin oldukça fazla çıkması bu modelin çözümleme için uygun olmadığını göstermektedir.

Çizelge 5. Su için elde edilen sonuçların doğrulanması

\begin{tabular}{|c|c|c|c|}
\hline Bağlantı parçası & $\mathbf{K}_{\mathbf{k}}(\mathbf{k}-\mathbf{\varepsilon})$ & $\mathbf{K}_{\mathbf{k}}(\mathbf{k}-\boldsymbol{\omega})$ & $\mathbf{K}_{\mathbf{k}}[\mathbf{1 9}]$ \\
\hline $\mathbf{T}$ & 2,008 & 1,839 & 2 \\
\hline $\mathbf{L}$ & 1,145 & 0,932 & 1,1 \\
\hline
\end{tabular}


L ve $T$ Tesisat Bağlantı Elemanlarında Nanoakışkan Kullanımında Akış Karakteristiklerinin Sayısal Olarak Incelenmesi

\subsubsection{Su- $\mathrm{Al}_{2} \mathrm{O}_{3}$ Nanoakışkanı için Elde Edilen Sonuçlar}

Çizelge 6 ve 7'te değişen hacim konsantrasyonlarına göre her bir bağlantı parçası için hesaplanan kayıp katsayıları sırasıyla k- $\varepsilon$ ve k$\omega$ türbülans modeli için verilmiştir. Her iki çizelgeden de görüldüğü gibi konsantrasyonun artmasıyla yerel kayıp katsayıları artmıștır. Akışın türbülanslı bölgede oluşu, nanoakışkan hacim konsantrasyonuna bağlı olarak hız, yoğunluk ve viskozitedeki artışlar basınç farkında ve yerel kayıp katsayısında ciddi artışlar meydana getirmektedir. Standart k- $\omega$ türbülans modeli kullanılarak su için hesaplanan yerel kayıp katsayılarının literatürde kabul edilen [19] değerden daha fazla çıkması çözümlemede kullanılan türbülans modelinin uygun olmadiğ sonucunu ortaya koymuştur. Buna rağmen bundan sonraki bölümlerde de türbülans modelleri arasındaki farkın görülebilmesi için yaygın olarak kullanılan her iki modelin sonuçlarına yer verilmiştir.

Çizelge 6. Bağlantı parçalarının kayıp katsayıları, $\mathrm{K}_{\mathrm{k}}, \mathrm{k}-\varepsilon$ modeli $\left(\mathrm{Al}_{2} \mathrm{O}_{3}\right)$

\begin{tabular}{|l|c|c|}
\hline \multirow{2}{*}{ Akışkanlar } & \multicolumn{2}{|c|}{ Kayıp katsayıları, $\mathbf{K}_{\mathbf{k}}$} \\
\cline { 2 - 3 } & $\mathbf{L}$ & $\mathbf{T}$ \\
\hline $\mathrm{Su}$ & 1,145 & 2,008 \\
\hline $\mathrm{Su}+\% 0,3 \mathrm{Al}_{2} \mathrm{O}_{3}$ & 1,153 & 2,024 \\
\hline $\mathrm{Su}+\% 0,5 \mathrm{Al}_{2} \mathrm{O}_{3}$ & 1,60 & 2,036 \\
\hline $\mathrm{Su}+\% 1,0 \mathrm{Al}_{2} \mathrm{O}_{3}$ & 1,179 & 2,071 \\
\hline $\mathrm{Su}+\% 2,0 \mathrm{Al}_{2} \mathrm{O}_{3}$ & 1,210 & 2,124 \\
\hline $\mathrm{Su}+\% 3,0 \mathrm{Al}_{2} \mathrm{O}_{3}$ & 1,242 & 2,180 \\
\hline
\end{tabular}

Çizelge 7. Bağlantı parçalarının kayıp katsayıları, $\mathrm{K}_{\mathrm{k}}, \mathrm{k}-\omega$ Modeli $\left(\mathrm{Al}_{2} \mathrm{O}_{3}\right)$

\begin{tabular}{|l|c|c|}
\hline \multirow{2}{*}{ Akışkanlar } & \multicolumn{2}{|c|}{ Kayıp katsayıları, $\mathbf{K}_{\mathbf{k}}$} \\
\cline { 2 - 3 } & $\mathbf{L}$ & $\mathbf{T}$ \\
\hline $\mathrm{Su}$ & 0,932 & 1,839 \\
\hline $\mathrm{Su}+\% 0,3 \mathrm{Al}_{2} \mathrm{O}_{3}$ & 0,939 & 1,925 \\
\hline $\mathrm{Su}+\% 0,5 \mathrm{Al}_{2} \mathrm{O}_{3}$ & 0,945 & 1,922 \\
\hline $\mathrm{Su}+\% 1,0 \mathrm{Al}_{2} \mathrm{O}_{3}$ & 0,960 & 1,970 \\
\hline $\mathrm{Su}+\% 2,0 \mathrm{Al}_{2} \mathrm{O}_{3}$ & 0,985 & 2,104 \\
\hline $\mathrm{Su}+\% 3,0 \mathrm{Al}_{2} \mathrm{O}_{3}$ & 1,011 & 2,242 \\
\hline
\end{tabular}

L bağlantı parçasında akış, keskin bir dönüş ile yönünü $90^{\circ}$ değiştirmeye zorlanmaktadır. Akışta dönüş esnasında keskin köşelerde girdaplar meydana gelir. Bu durumda akışın enerjisi düşer ve bu da basınç kaybıyla sonuçlanır. Yerel kayıp katsayısındaki bu artış, viskozite ve yoğunluktaki artış ile doğrudan ilişkilendirilebilir. Seçilen $\mathrm{T}$ bağlantı parçasının, giriş ve çıkış çap1 aynı seçilmiştir, böylece kesitte herhangi bir değişiklik yapmadan sadece akışın yönü değiştirilmiştir. Bu bağlantı parçasında meydana gelen enerji kayıpları, iç tarafta akışın ayrılmasından ve keskin dönüşlerin meydana getirdiği girdaplı akışlardan kaynaklanmaktadır. 
Şekil 2'de L bağlantı parçasının artan hacim konsantrasyona bağlı basınç ve hız dağılımları görülmektedir. Düşük konsantrasyonlarda $0,8 \mathrm{~Pa}$ mertebesinde olan maksimum basinç, konsantrasyon artışı ile 7, Pa mertebesine kadar çıkmıştır. L bağlantı parçasındaki bu basınç artışı akışın keskin köşelerde girdapların meydana

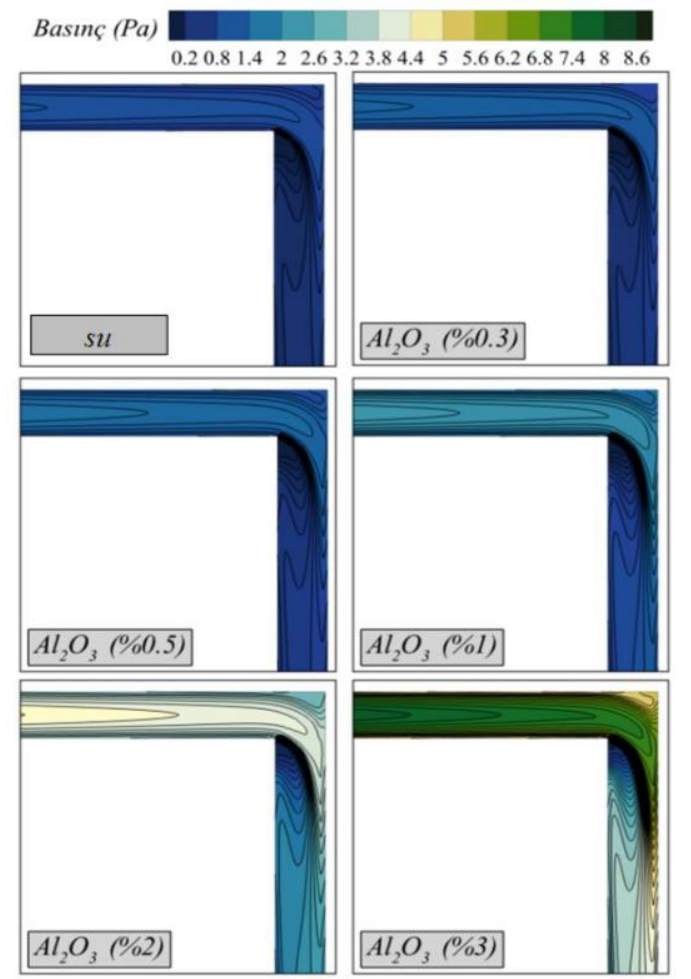

gelmesi ile ilişkilendirilebilir. Buralarda akış enerjisini kaybeder doğal olarak basınç kaybı artar. Çizelgelerde görüldüğü gibi bu durum da basınç farkının ve yerel kayıp katsayısının artışına sebep olmaktadır. Hız dağılımları göz önüne alındığında da $\mathrm{Al}_{2} \mathrm{O}_{3}$ konsantrasyonunun artışı ile hızın artı̆̆ görülmektedir.

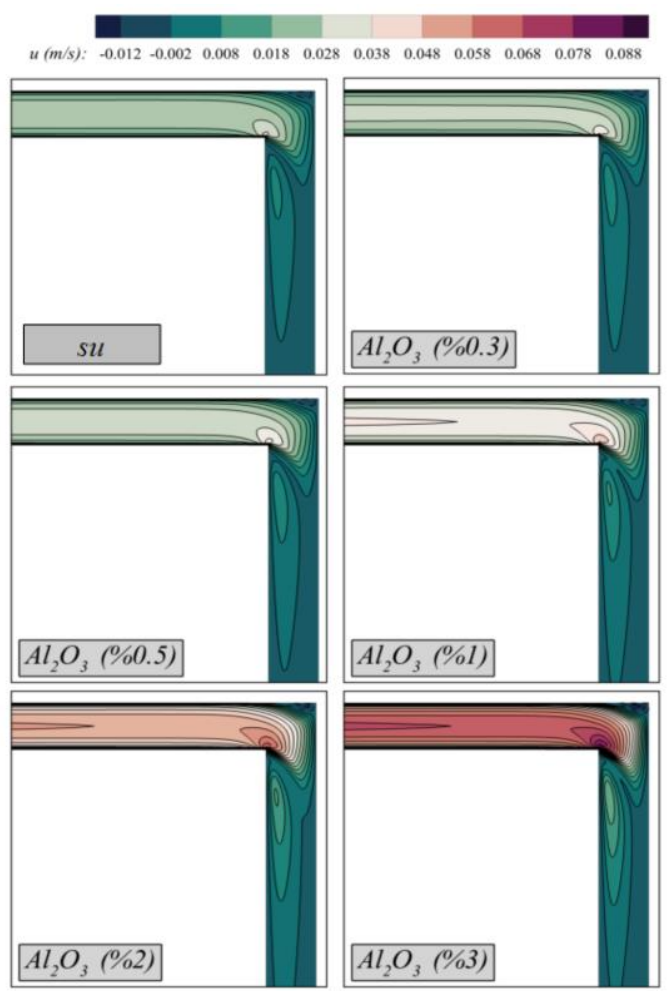

Şekil 2. $\mathrm{L}$ bağlantı parçası için basınç ve hız dağılımı $\left(\mathrm{Al}_{2} \mathrm{O}_{3}\right)$

Şekil 3'te $\mathrm{T}$ bağlantı parçası için artan konsantrasyonun basınç ve hız dağılımı üzerine etkisi verilmiştir. Çizelgelerde de belirtildiği gibi, nanoakışkan konsantrasyonundaki artışla birlikte basınç dağılımı da değişmektedir. Düşük konsantrasyonlarda $0,4 \mathrm{~Pa}$ mertebesinde olan basınç en yüksek konsantrasyonda 4,8 $\mathrm{Pa}$ mertebesine kadar ulaşmıştır. Dağılım olarak bütün şekillerde geometrinin tamamının verilmediği, sadece akış için önemli olan yerlerin yakınlaştırılarak sunulduğu göz önünde bulundurulmalıdır. T bağlantı parçasında da akışın kollara ayrıldı̆̆ı keskin köşelerde, girdaplı akıştan dolayı ölü akış bölgesi meydana geldiği ve basıncın diğer bölgelere göre çok daha fazla düştüğü görülmektedir. Beklendiği gibi $\mathrm{T}$ bağlantı parçası için $\mathrm{Al}_{2} \mathrm{O}_{3}$ nanoakışkanında konsantrasyon artışı ile hız artmıştır. T bağlantı parçasında akışın kollara ayrıldığı keskin köşelerde, akış yön değiştirir. Kesikli çizgilerle gösterilen negatif hızlar akışın yön değiştirdiğini göstermektedir. 
L ve $T$ Tesisat Bağlantı Elemanlarında Nanoakışkan Kullanımında Akış Karakteristiklerinin Sayısal Olarak Incelenmesi
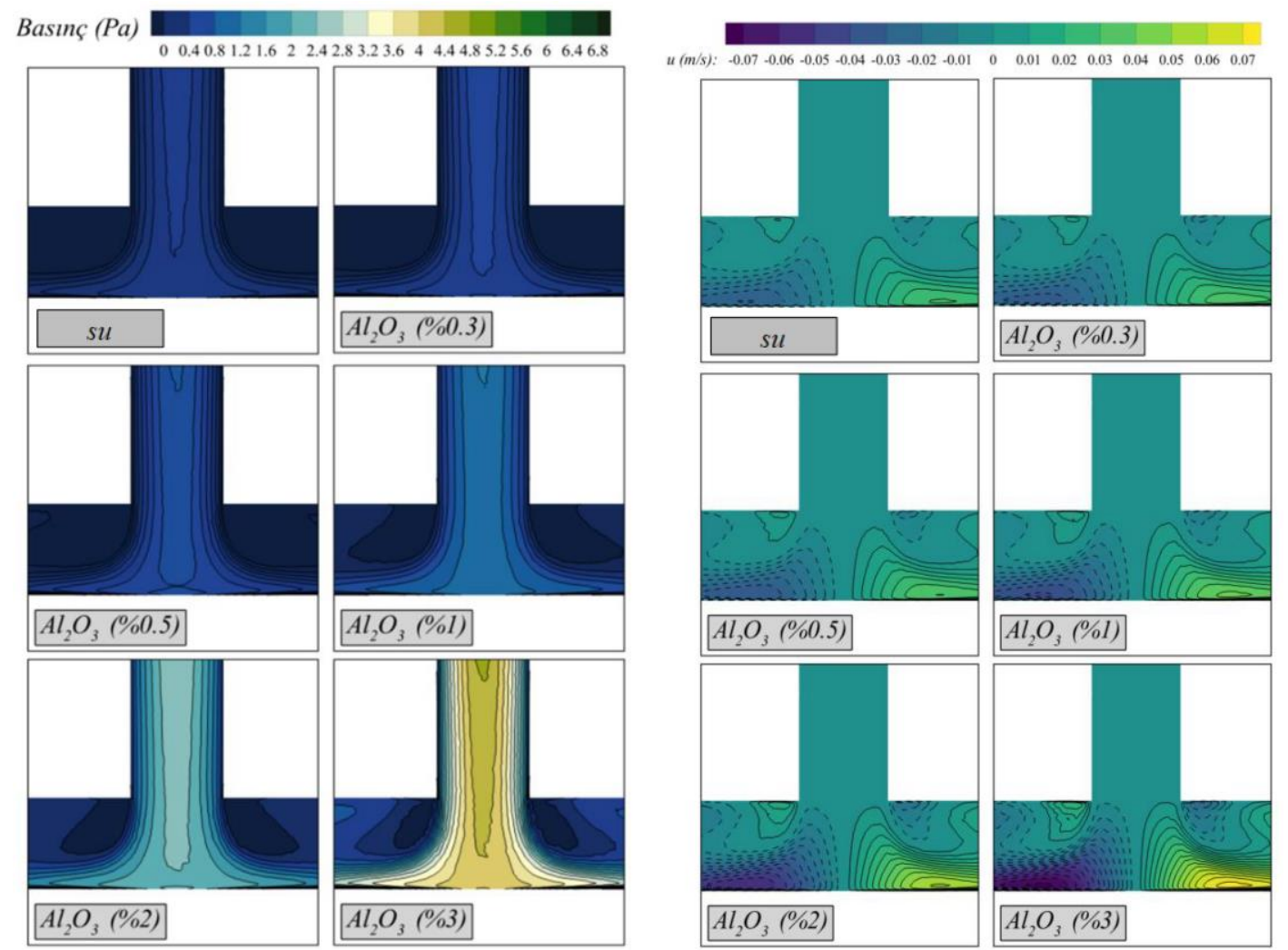

Şekil 3. $\mathrm{T}$ bağlantı parçası için basınç ve hız dağılımı $\left(\mathrm{Al}_{2} \mathrm{O}_{3}\right)$

Ele alınan nanoakışkan için hacim konsantrasyonunun artması ile basınç farkının arttığı görülmüştür. Çünkü basınç farkı konsantrasyonun bir fonksiyonudur. Konsantrasyon arttıkça basınç farkı da artar. Bunun nedeni ise viskozitenin konsantrasyonla artmasidir. Partiküllerin yoğunluğunun artışı ile türbülans veya çalkantılar artarak moleküllerin hareketi zorlaşır, bu da basınç farkını artırır.

\subsubsection{Su-CuO Nanoakışkanı İçin Elde Edilen Sonuçlar}

Su-CuO nanoakışkanı için farklı türbülans modellerinde hesaplanan yerel kayıp değerleri Çizelge 8 ve Çizelge 9'da özetlenmiştir. Her iki bağlantı parçasında da kayıp katsayısı artan konsantrasyonla artmaktadır. T bağlantı parçasında akışın ayrılması, keskin dönüşlerde girdap oluşması akış hızını ve yerel kayıp katsayısını arttırmıştır. 
Çizelge 8. Bağlantı parçalarının kayıp katsayıları, $\mathrm{K}_{\mathrm{k}}, \mathrm{k}-\varepsilon$ modeli $(\mathrm{CuO})$

\begin{tabular}{|c|c|c|}
\hline \multirow{2}{*}{ Akıskanlar } & \multicolumn{2}{|c|}{ Kayıp katsayıları, $\mathbf{K}_{\mathbf{k}}$} \\
\cline { 2 - 3 } & $\mathbf{L}$ & $\mathbf{T}$ \\
\hline $\mathrm{Su}+\% 1 \mathrm{CuO}$ & 1,205 & 1,992 \\
\hline $\mathrm{Su}+\% 2 \mathrm{CuO}$ & 1,265 & 2,093 \\
\hline $\mathrm{Su}+\% 4 \mathrm{CuO}$ & 1,387 & 2,295 \\
\hline
\end{tabular}

$\operatorname{Basınç(Pa)}$
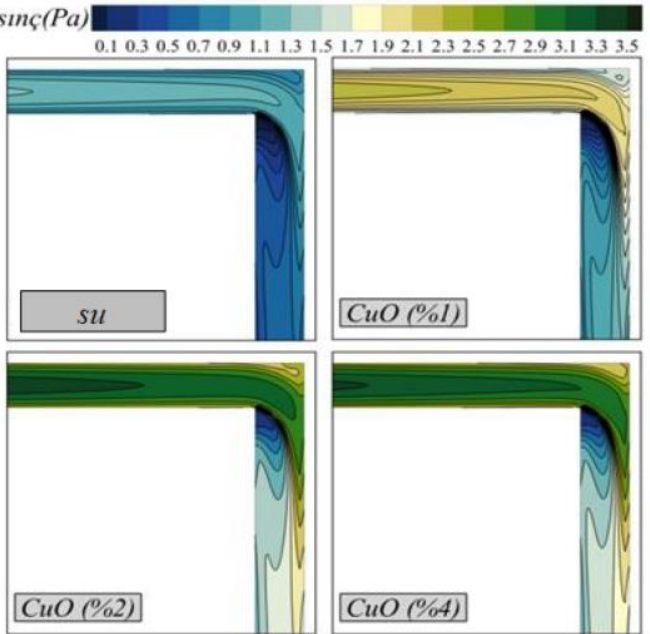

Çizelge 9. Bağlantı parçalarının kayıp katsayıları,

\begin{tabular}{|c|c|c|}
\hline \multirow{2}{*}{$\mathrm{K}_{\mathrm{k}}, \mathrm{k}-\omega$ modeli $(\mathrm{CuO})$} \\
\cline { 2 - 3 } Akışkanlar & \multicolumn{2}{|c|}{ Kayıp katsayıları, $\mathbf{K}_{\mathbf{k}}$} \\
\cline { 2 - 3 } & $\mathbf{L}$ & $\mathbf{T}$ \\
\hline $\mathrm{Su}+\% 1 \mathrm{CuO}$ & 0,981 & 2,115 \\
\hline $\mathrm{Su}+\% 2 \mathrm{CuO}$ & 1,032 & 2,280 \\
\hline $\mathrm{Su}+\% 4 \mathrm{CuO}$ & 1,130 & 2,416 \\
\hline
\end{tabular}

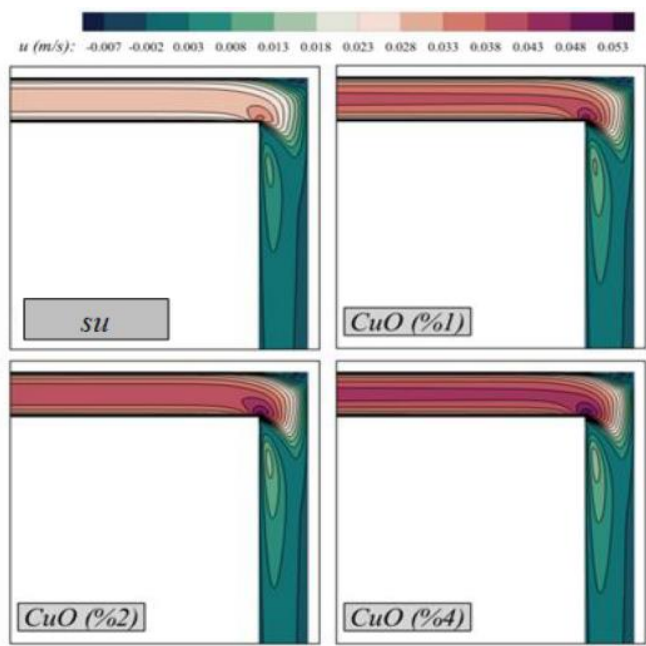

Şekil 4. L Bağlantı parçası için basınç ve hız dağılım dağılımları $(\mathrm{CuO})$

Basınç $(\mathrm{Pa})$

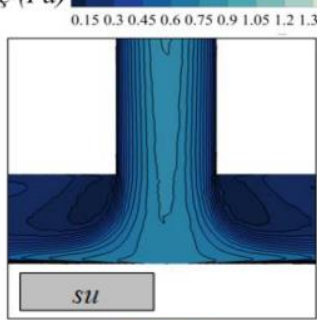

1.51 .651 .81 .952 .12 .252 .42 .552 .72 .853
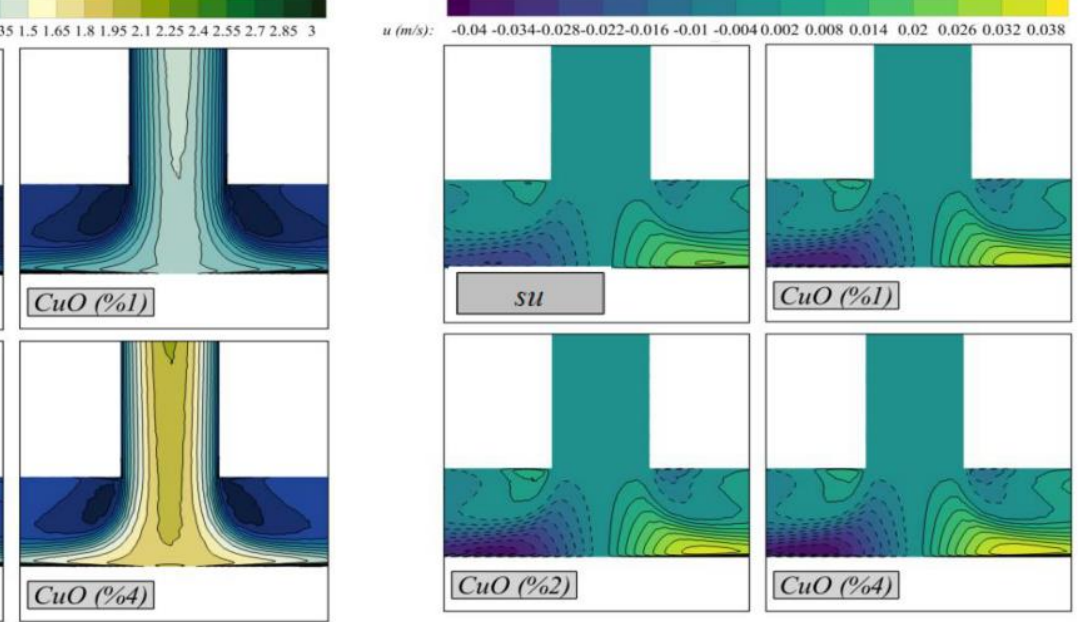

$\mathrm{CuO}(\% 2)$

Şekil 5. T bağlantı parçası için basınç ve hız dağılımları $(\mathrm{CuO})$

\subsection{3. $\mathrm{Su}-\mathrm{TiO}_{2}$ Nanoakışkanı için Elde Edilen Sonuçlar}

$\mathrm{Su}-\mathrm{TiO}_{2}$ nanoakışkanı için farklı türbülans modellerinde hesaplanan basınç ve yerel kayıp katsayıları Çizelge 10 ve 11'de sunulmuştur. İncelenen diğer nanoakışkanlarda olduğu gibi su$\mathrm{TiO}_{2}$ nanoakışkanında da bütün bağlantı malzemelerindeki kayı katsayıları artan konsatrasyonla birlikte artmıştır. Şekil 6'da L 
L ve T Tesisat Bă̆lantı Elemanlarında Nanoakışkan Kullanımında Akış Karakteristiklerinin Sayısal Olarak Incelenmesi

bağlantı parçası için basınç ve hız dağılımları artan konsantrasyonlara bağlı olarak sunulmuştur. En düşük konsantrasyonda okunan maksimum basınç 0,75 Pa mertebesinde iken konsantrasyon artışı ile 1,05 $\mathrm{Pa}$ mertebesine kadar ulaşmıştır. Akış ayrılmalarının olduğu kısımlarda enerji kayıplarından dolayı basınç çok fazla azalmıştır. Hız dağılımlarının özellikle keskin köşelerde daha çok sıklaştığı, hız ise yine ayrılmaların olduğu yerlerde azaldığı görülmüştür.
Şekil 7'de artan konsantrasyona bağlı olarak T bağlantı parçası için basınç ve hız dağılımları gösterilmiştir. Akışın kollara ayrıldığ bölgelerde basınç dağılımları sıklaşmıştır. T bağlantı parçası için akış ayrılmalarının olduğu yerlerde hız dağılımlarının sıklaştığı görülmektedir. Keskin dönüşlerin olduğu girdap kopmalarında akış ters yönde hareket etmektedir. Şekil 7'deki kesikli çizgiler, akışın yön değiştirdiğini göstermektedir.

Çizelge 10. Bağlantı parçalarının kayıp katsayıları, $\mathrm{K}_{\mathrm{k}}, \mathrm{k}-\varepsilon$ modeli $\left(\mathrm{TiO}_{2}\right)$

\begin{tabular}{|c|c|c|}
\hline \multirow{2}{*}{ Akışkanlar } & L & Kayı katsayıları, $\mathbf{K}_{\mathbf{k}}$ \\
\cline { 2 - 3 } & 1,094 & 2,00 \\
\hline $\mathrm{Su}+\% 0,05 \mathrm{TiO}_{2}$ & 1,172 & 2,138 \\
\hline $\mathrm{Su}+\% 0,1 \mathrm{TiO}_{2}$ & 1,134 & 2,711 \\
\hline $\mathrm{Su}+\% 0,3 \mathrm{TiO}_{2}$ & 1,369 & 3,282 \\
\hline $\mathrm{Su}+\% 0,5 \mathrm{TiO}_{2}$ & \multicolumn{2}{c}{} \\
\hline
\end{tabular}

Çizelge 11. Bağlantı parçalarının kayıp katsayıları, $\mathrm{K}_{\mathrm{k}}, \mathrm{k}-\omega$ modeli $\left(\mathrm{TiO}_{2}\right)$

\begin{tabular}{|c|c|c|}
\hline \multirow{2}{*}{ Akışkanlar } & \multicolumn{2}{|c|}{ Kayıp katsayıları, $\mathbf{K}_{\mathbf{k}}$} \\
\cline { 2 - 3 } & $\mathbf{L}$ & $\mathbf{T}$ \\
\hline $\mathrm{Su}+\% 0,05 \mathrm{TiO}_{2}$ & 1,002 & 2,286 \\
\hline $\mathrm{Su}+\% 0,1 \mathrm{TiO}_{2}$ & 1,434 & 2,979 \\
\hline $\mathrm{Su}+\% 0,3 \mathrm{TiO}_{2}$ & 1,363 & 3,777 \\
\hline $\mathrm{Su}+\% 0,5 \mathrm{TiO}_{2}$ & 1,655 & 4,517 \\
\hline
\end{tabular}

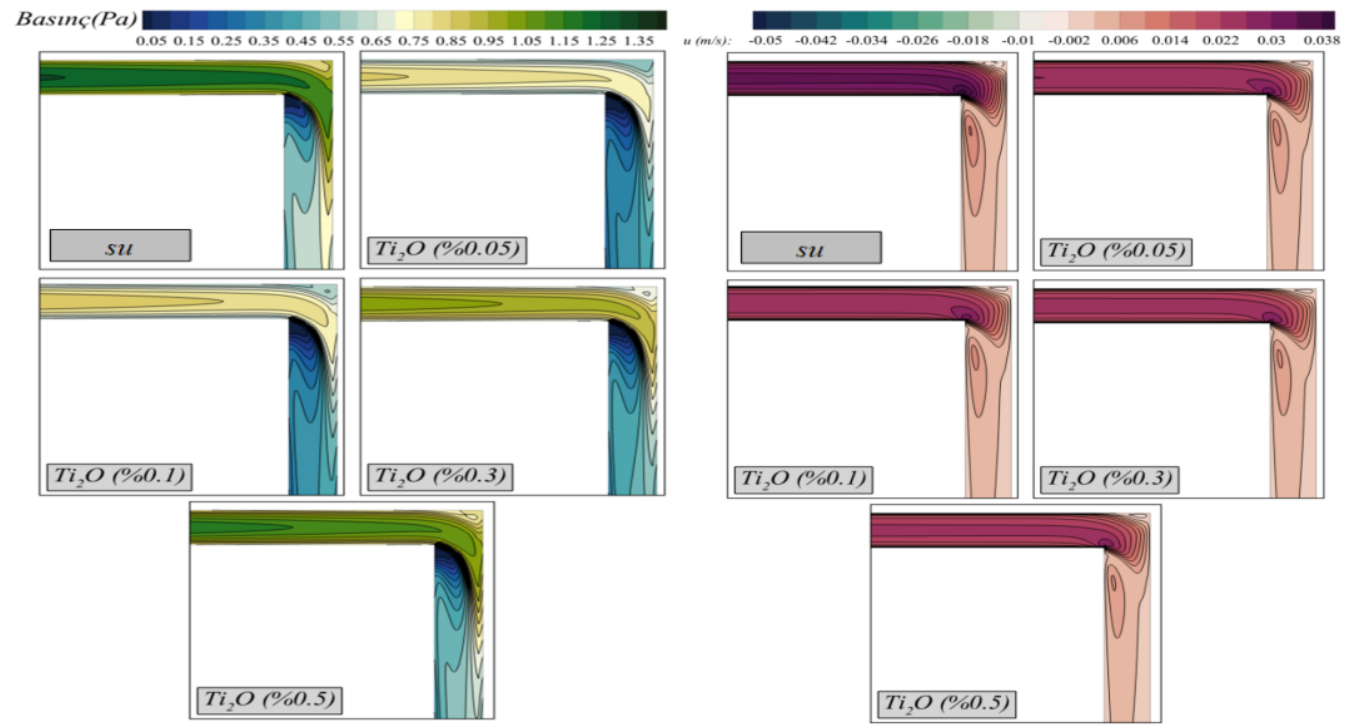

Şekil 6. L Bağlantı Parçası için basınç ve hız dağılımları $\left(\mathrm{TiO}_{2}\right)$ 

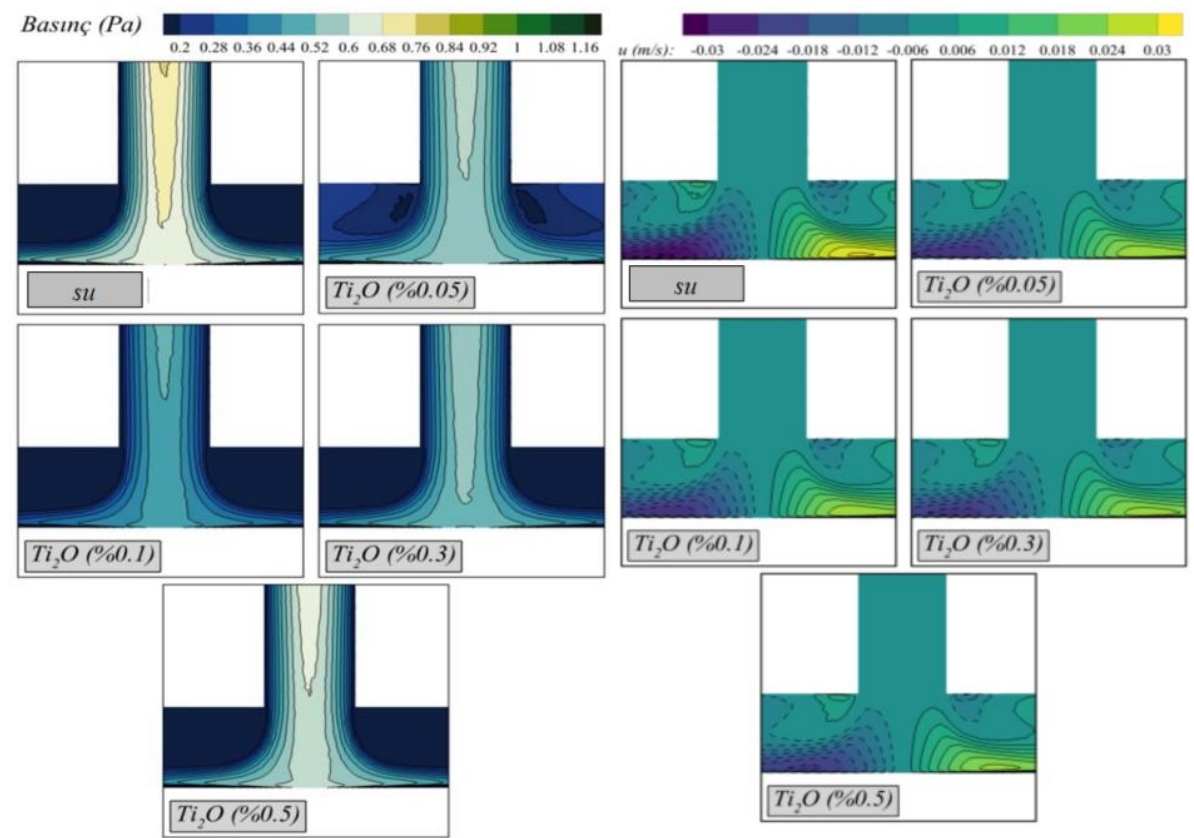

Şekil 7. $\mathrm{T}$ bağlantı parçası için basınç ve hız dağılımları $\left(\mathrm{TiO}_{2}\right)$

$\mathrm{TiO}_{2}$ nanoakışkanın 4 farklı hacim konsantrasyonu da ele alındığında konsantrasyonun artışı ile basınç farkının da arttığı görülmektedir. Basınç farklarıyla hesaplanan yerel kayıp katsayı değerinin de arttığ1 görülmüştür. Türbülans modellerin uygunluğu diğer nanoakışkanlarla aynıdır.

\subsection{Farklı Nanoakışkanların Farklı Konsantrasyonlarında Pompa Gücü}

Farklı hacim konsantrasyonlarında farklı nanoakışkanlar için eşitlik 13 yardımıyla elde edilmiş pompa gücü grafikleri Şekil 8, 9 ve 10'da verilmiştir. Bütün nanoakışkanlar ve bütün konsantrasyonlarda en yüksek basınç farkının $\mathrm{T}$ bağlantı parçasında meydana geldiği görülmüştür. Bunun sebebi, gerçek akış şartlarında, sürtünmenin sebep olduğu enerji kaybı nedeniyle, akışkan içinde ve akış istikametinde farklı iki nokta arasındaki enerji azalan bir eğilim gösterir. Bağlantı parçası girişindeki yük kaybı geometriye bağlıdır. Bağlantı parçaları için $\mathrm{TiO}_{2}$ nanoakışkanının birçok farklı konsantrasyonu ele alınıp incelenmiş sonuçlar Şekil 10'da verilmiştir. Genel itibariye hacimsel konsantrasyon arttıkça nanoakışkan viskozitesi artmaktadır. Burada diğer nanoakışkanların aksine viskozitenin artmasıyla akış hızı azalmıştır. Çünkü $\mathrm{TiO}_{2}$ nanoakışkanının dinamik viskozitedeki ve yoğunluk oranlarındaki artış oranı diğer nanoakışkanlar ile kıyaslandığında çok daha düşüktür. Konsantrasyon değeriyle birlikte yoğunluk ve dinamik viskozitedeki artmış olsa bile düşük artış oranı bunun önüne geçmiş ve hız azalmıştır. Buna ek olarak hacimsel konsantrasyonun ve Reynolds sayısının artışı da sonuç itibariyle basınç farkının artmasına neden olmuştur. Nanoakışkanların konsantrasyonu arttıkça gerekli duyulan pompa gücü de kayıpların artmasına bağlı olarak belirgin bir artış gözlenmiştir. Gerekli pompa gücü için Reynolds sayısı, giriş hızı, hacimsel debi, basınç farkı gibi faktörler büyük önem taşımaktadır. Tesisatlarda pompa seçimi bilindiği gibi; öncelikle enerji verimliliği ve maliyet açısından çok önem arz etmektedir. Buna ek olarak pompanın birlikte kullanılacağı akışkanın yoğunluğu, viskozitesi, pompanın tipi ve bağlanacağı tesisat da önemli kriterler arasındadır. Bunun için tesisatlarda temel akışkan yerine iletkenliği yüksek nanoakışkan kullanımının ısı transferini arttırdığı durumu ele alınmalı, nanoakışkanların yerel kayıpları ve basınç kayıplarını arttırması durumu göz ardı edilmelidir. 
L ve $T$ Tesisat Bağlantı Elemanlarında Nanoakışkan Kullanımında Akış Karakteristiklerinin Sayısal Olarak Incelenmesi

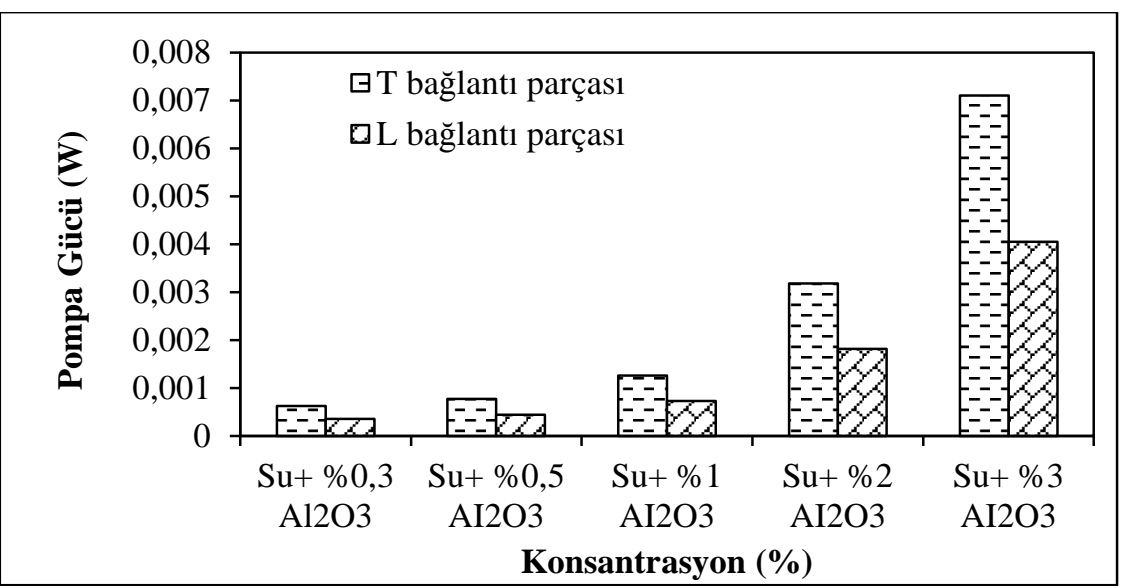

Şekil 8. $\mathrm{AI}_{2} \mathrm{O}_{3}$ nanoakışkanının farklı konsantrasyonlarda pompa gücünün $(\mathrm{W})$ artışı

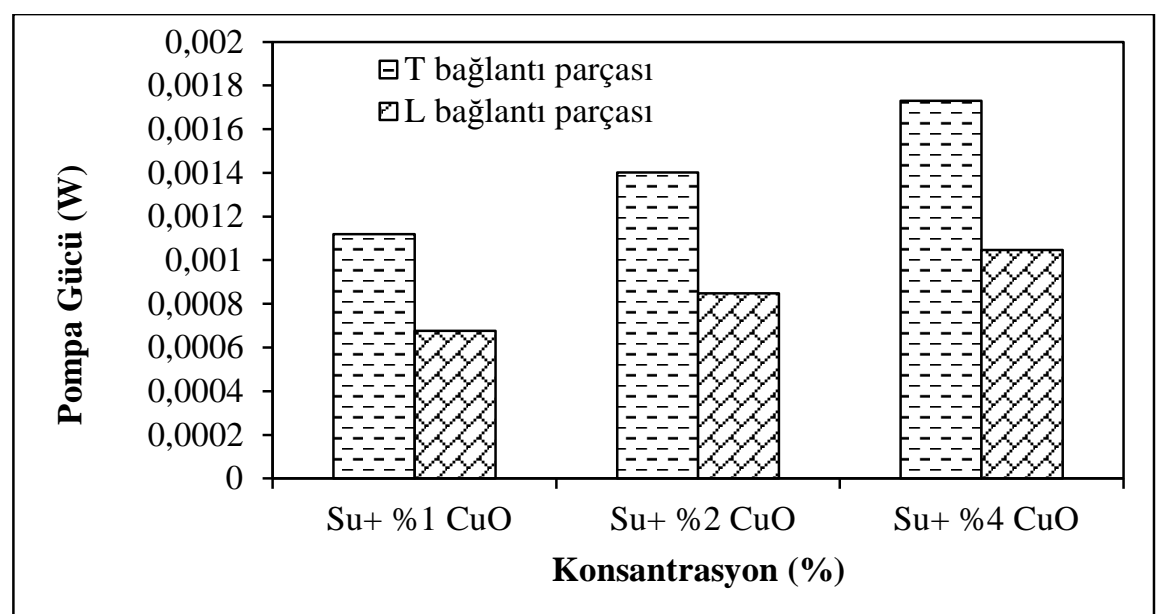

Şekil 9. CuO nanoakışkanının farklı konsantrasyonlarda pompa gücünün (W) artışı

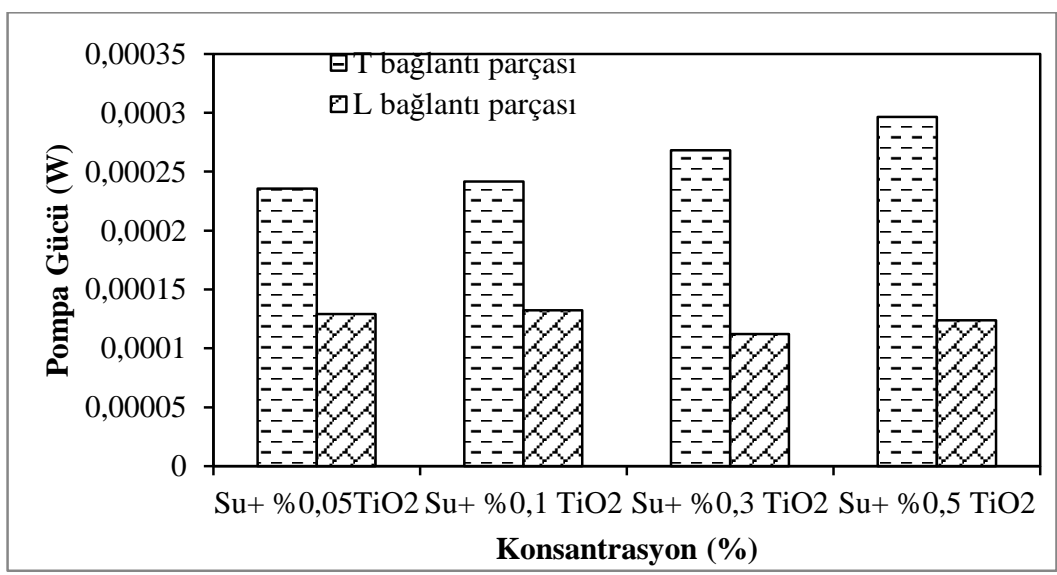

Şekil 10. $\mathrm{TiO}_{2}$ nanoakışkanının farklı konsantrasyonlarda pompa gücünün $(\mathrm{W})$ artışı 


\section{SONUÇLAR VE ÖNERILER}

$\mathrm{Bu}$ çalışmada farklı tipte tesisat bağlantı parçalarının içerisinden su yerine nanoakışkan geçirilmesi durumunda oluşan yerel kayıp katsayıları sayısal olarak incelenmiştir. Tesisatlarda en çok kullanılan 2 farklı bağlantı parçası ( $\mathrm{L}$ ve T) seçilip, bu bağlantı parçalarının içerisinden alüminyum, bakır ve titanyum esaslı nanopartiküllerin eklenmesiyle oluşan nanoakışkanlar geçirilmiş ve basınç düşüşleri sayısal olarak hesaplanmıştır.

Nanoakışkanların konsantrasyonu arttıkça yerel kayıp katsayısı değerinin ve basınç farkının nasıl etkilendiği incelenmiştir. Nanoakışkan kullanılması durumunda basınç kaybının arttığı görülmüştür. Basınç kaybının artışında; $\mathrm{Al}_{2} \mathrm{O}_{3}, \mathrm{CuO}$ ve $\mathrm{Ti}_{2} \mathrm{O}$ nanoakışkanlarını oluşturan nanopartiküllerin sabit sıcaklık altındaki termofiziksel özellikleri, hacim konsantrasyonları, akışın türbülanslı ya da laminar şartlar altındaki karakteristik özelliğinin çok fazla etkili olduğu ortaya konulmuştur. Hacim konsantrasyonlarındaki artışa bağlı olarak dinamik viskozitenin artışı ile basınç farkının da arttığ görülmüştür. Sayısal çözümlemelerde Standart k- $\varepsilon$, k- $\omega$ Standart türbülans modeli olmak üzere iki farklı model kullanılmıştır. Bütün bağlantı parçaları için en uygun modelin $\mathrm{k}-\varepsilon$ modelinin uygun sonuçları verdiği doğrulanmıştır.

\section{TEŞEKKÜR}

Sunulan bu çalışma, Mürüvvet Avcı'nın Dr. Nehir TOKGÖZ danışmalığında yürüttüğü yüksek lisans tezinin bir parçasıdır.

\section{KAYNAKLAR}

1. Bergles, A., 1983. Augmentation of Heat Transfer, Heat Exchanger Design Handbook, Hemisphere Publishing, New York, secs, 2, 489-501.

2. Şahin, B., Çomaklı, K., Çomaklı, Ö., Yılmaz, M., 2006. Nanoakışkanlarla Isı Transferinin İyileştirilmesi, Mühendis Makine, 559, 29-34.

3. Choi, S.U., Eastman, J.A., 1995. Enhancing Thermal Conductivity of Fluids with
Nanoparticles, in, Argonne National Lab., IL (United States).

4. Murshed, S., Leong, K., Yang, C., 2008. Thermophysical and Electrokinetic Properties of Nanofluids-a Critical Review, Applied Thermal Engineering, 28, 2109-2125.

5. Ganvir, R., Walke, P., Kriplani, V., 2017. Heat Transfer Characteristics in Nanofluid-a Review. Renewable and Sustainable Energy Reviews, 75, 451-460.

6. Hassanzadeh, R., Tokgoz, N., 2017. Thermalhydraulic Characteristics of Nanofluid Flow in Corrugated Ducts., Journal of Engineering Thermophysics, 26, 498-513.

7. Tokgoz, N., 2018. The Numerical Study of Heat Transfer Enhancement Using $\mathrm{Al}_{2} \mathrm{O}_{3}$-water Nanofluid in Corrugated Duct Application, Journal of Thermal Engineering, 4(3), 1984-1997. DOI: 10.18186/journal-of-thermalengineering.409655

8. Ahmed, M., Shuaib, N., Yusoff, M.Z., AlFalahi, A., 2011. Numerical Investigations of Flow and Heat Transfer Enhancement in a Corrugated Channel Using Nanofluid, International Communications in Heat and Mass Transfer, 38, 1368-1375.

9. Sasmito, A.P., Kurnia, J.C., Mujumdar, A.S., 2011. Numerical Evaluation of Laminar Heat Transfer Enhancement in Nanofluid Flow in Coiled Square Tubes. Nanoscale Research Letters, 6, 1-14.

10. Godson, L., Raja, B., Lal, D.M., Wongwises, S.E.A., 2010. Enhancement of Heat Transfer Using Nanofluids-an Overview, Renewable and Sustainable Energy Reviews, 14, 629-641.

11. Manay, E., Şahin, B., Akyürek, E.F., Çomaklı, Ö., 2012. Mikrokanallarda Nanoakışkanların Kullanımı, TMMOB MMO Mühendis ve Makina Dergisi, 53(627), 38-42

12. Hashemi, S., Akhavan-Behabadi, M., 2012. An Empirical Study on Heat Transfer and Pressure Drop Characteristics of CuO-base Oil Nanofluid Flow in a Horizontal Helically Coiled Tube Under Constant Heat Flux, International Communications in Heat and Mass Transfer, 39, 144-151.

13. Ahmed, M., Shuaib, N., Yusoff, M.Z., 2012. Numerical Investigations on the Heat Transfer Enhancement in a Wavy Channel Using 
Nanofluid, International Journal of Heat and Mass Transfer, 55, 5891-5898.

14. Kabeel, A., Abou El Maaty, T., El Samadony, Y., 2013. The Effect of Using Nano-particles on Corrugated Plate Heat Exchanger Performance. Applied Thermal Engineering, 52, 221-229.

15. Chavda, N., Jani, J.P., Patel, A.K., Zala, K.P., Nimbark, N.G., 2014. Effect of Nanofluid on Friction Factor of Pipe and Pipe Fittings: Part IEffect of Aluminum Oxide Nanofluid. International Journal of Current Engineering and Technology, 4, 4069-4074.

16. Barik, A.K., Satapathy, P.K., Sahoo, S.S., 2016. CFD Study of Forced Convective Heat Transfer Enhancement in a $90^{\circ}$ Bend Duct of Square Cross Section Using Nanofluid, Sādhanā 41, 795-804.

17. Vasa, A., Barik, A.K., Nayak, B., 2017. Turbulent Convection Heat Transfer Enhancement in a 180-degree U-bend of Triangular Cross-section Using Nanofluid, in: IOP Conference Series: Materials Science and Engineering, IOP Publishing, 012067.

18. Mohamad, A., 2015. Myth About Nano-fluid Heat Transfer Enhancement, International Journal of Heat and Mass Transfer, 86, 397-403.

19. Çengel, Y., Cimbala, J.M., Engin, T., 2008. Akışkanlar Mekaniği: Temelleri ve Uygulamaları, Güven Kitabevi.

20. Kim, J., Yadav, M., Kim, S., 2014. Characteristics of Secondary Flow Induced by 90-degree Elbow in Turbulent Pipe Flow, Engineering Applications of Computational Fluid Mechanics, 8, 229-239.

21. Homicz, G.F., 2004. Computational Fluid Dynamic Simulations of Pipe Elbow Flow, in, Sandia National Laboratories.

22. Rahimzadeh, H., Maghsoodi, R., Sarkardeh, H., Tavakkol, S., 2012. Simulating Flow Over Circular Spillways by Using Different Turbulence Models, Engineering Applications of Computational Fluid Mechanics, 6, 100-109.

23. Wilcox, D.C., 1988. Reassessment of the ScaleDetermining Equation for Advanced Turbulence Models, AIAA Journal, 26, 1299-1310.

24. Özbey, M., 2016. Experimental Study on Pressure Drop of Aluminum-oxide/water
Nanofluids. Journal of Thermophysics and Heat Transfer, 30, 342-349.

25. Bedir, Ö., 2013. Sabit Isı Ak1lı Yatay Bir Boruda Zorlanmış Türbülanslı Akışta Nanoakışkanların Sayısal İncelenmesi, Atatürk Üniversitesi, Fen Bilimleri Enstitüsü, Doktora Tezi, Erzurum, 118.

26. Gedik, E., Kayfeci, M., Keçebaş, A., Kurt, H., 2017. Dairsel Bir Boruda $\mathrm{Al}_{2} \mathrm{O}_{3} / \mathrm{su}$ ve $\mathrm{TiO}_{2} / \mathrm{su}$ Nanoakışkanların Laminer Zorlanmış Isı Taşınımı, TTMD Dergisi, 48-53. 